\section{(6) OPEN ACCESS}

\title{
Association between exposure to ambient particulate matter and chronic obstructive pulmonary disease: results from a cross-sectional study in China
}

Sha Liu, ${ }^{1}$ Yumin Zhou, ${ }^{1}$ Suixin Liu, ${ }^{2}$ Xinyu Chen, ${ }^{3}$ Weifeng Zou, ${ }^{4}$ Dongxing Zhao, ${ }^{1}$ Xiaochen Li, ${ }^{1}$ Jinding $\mathrm{Pu}^{1}{ }^{1}$ Lingmei Huang, ${ }^{1}$ Jinlong Chen, ${ }^{1}$ Bing Li, ${ }^{5}$ Shiliang Liu, ${ }^{6,7}$ Pixin $\operatorname{Ran}^{1}$

- Additional material is published online only. To view please visit the journal online (http://dx.doi.org/10.1136/ thoraxjnl-2016-208910).

For numbered affiliations see end of article.

Correspondence to Dr Pixin Ran, The State Key Laboratory of Respiratory Disease, Guangzhou Institute of Respiratory Disease, The First Affiliated Hospital, Guangzhou Medical University, Guangzhou, Guangdong 510120, China; pxran@vip.163.com

Received 18 May 2016 Revised 14 October 2016 Accepted 17 October 2016 Published Online First 9 December 2016

\section{SLinked}

- http://dx.doi.org/10.1136/ thoraxjnl-2016-209687

\section{CrossMark}

To cite: Liu S, Zhou Y, Liu S, et al. Thorax

2017;72:788-795

\section{ABSTRACT}

Objective The association between exposure to ambient particles with a median aerodynamic diameter less than $10 / 2.5 \mu \mathrm{m}$ (particulate matter, $\mathrm{PM}_{10} / 2.5$ ) and COPD remains unclear. Our study objective was to examine the association between ambient $\mathrm{PM}_{10} / 2.5$ concentrations and lung functions in adults.

Methods A cross-sectional study was conducted in southern China. Seven clusters were randomly selected from four cities across Guangdong province. Residents aged $\geq 20$ years in the participating clusters were randomly recruited; all eligible participants were examined with a standardised questionnaire and spirometry. COPD was defined as a post-bronchodilator $\mathrm{FEV}_{1} / \mathrm{FVC}$ less than $70 \%$. Atmosphere PM sampling was conducted across the clusters along with our survey.

Results Of the subjects initially recruited, $84.4 \%$ $(n=5993)$ were included for analysis. COPD prevalence and atmosphere PM concentration varied significantly among the seven clusters. COPD prevalence was significantly associated with elevated PM concentration levels: adjusted OR 2.416 (95\% Cl 1.417 to 4.118$)$ for $>35$ and $\leq 75 \mu \mathrm{g} / \mathrm{m}^{3}$ and 2.530 (1.280 to 5.001) for $>75 \mu \mathrm{g} / \mathrm{m}^{3}$ compared with the level of $\leq 35 \mu \mathrm{g} / \mathrm{m}^{3}$ for $\mathrm{PM}_{2.5}$; adjusted OR 2.442 (95\% Cl 1.449 to 4.117$)$ for $>50$ and $\leq 150 \mu \mathrm{g} / \mathrm{m}^{3}$ compared with the level of $\leq 50 \mu \mathrm{g} / \mathrm{m}^{3}$ for $\mathrm{PM}_{1}$. A $10 \mu \mathrm{g} / \mathrm{m}^{3}$ increase in $\mathrm{PM}_{2.5}$ concentrations was associated with a $26 \mathrm{~mL}(95 \% \mathrm{Cl}$ -43 to -9$)$ decrease in $\mathrm{FEV}_{1}$, a $28 \mathrm{~mL}(-49$ to -8$)$ decrease in FVC and a $0.09 \%$ decrease $(-0.170$ to -0.010 ) in $\mathrm{FEV}_{1} / \mathrm{FVC}$ ratio. The associations of COPD with $\mathrm{PM}_{10}$ were consistent with $\mathrm{PM}_{2.5}$ but slightly weaker.

Conclusions Exposure to higher PM concentrations was strongly associated with increased COPD prevalence and declined respiratory function.

Trial registration number ChiCTR-00-14004264; Post-results.

\section{INTRODUCTION}

Air pollution has a significant public health impact that cannot be neglected. Outdoor air pollution may play an important role in the early development of respiratory disorders. ${ }^{12}$ Short-term (up to a few days) increases in exposure to outdoor air

\section{Key messages}

What is the key question?

- To find an association between exposure to ambient particles with a median aerodynamic diameter less than 10 or $2.5 \mu \mathrm{m}\left(\mathrm{PM}_{10 / 2.5}\right)$ and COPD and lung function in adults.

What is the bottom line?

- Through a population-based, cross-sectional, multicentre survey of COPD and 1-year ambient air sampling, we found that higher PM concentrations were strongly associated with COPD development and decreased respiratory function.

\section{Why read on?}

- Air pollution poses a big challenge to human health and the association between exposure to ambient particles and COPD is unclear. We used a multistage cluster sampling strategy to estimate COPD prevalence, sampling PM concentration with the guidance of the Institute of Earth Environment, Chinese Academy of Sciences. We considered almost all confounding factors to assess the association between PM concentration and COPD and lung function.

pollution have been found to increase the risk of adverse pulmonary outcomes, including acute exacerbation of COPD and respiratory mortality overall. $^{3}{ }^{4}$ Recent studies have associated shortterm exposure to outdoor particulate matter (PM) (particles with a median aerodynamic diameter less than 10 or $\left.2.5 \mu \mathrm{m}\left(\mathrm{PM}_{10} / 2.5\right)\right)$ with reduced lung function and increased hospital admissions. ${ }^{5-8}$ One study evaluated the relationship between annual average ambient fine $\mathrm{PM}_{2.5}$ concentrations and adverse respiratory outcomes (eg, asthma) for adults using modelled air pollution and health outcome data. ${ }^{9}$ In the European Study of Cohorts for Air Pollution Effects (ESCAPE), an increase of $10 \mu \mathrm{g} / \mathrm{m}^{3}$ in $\mathrm{PM}_{10}$ was found to be associated with a lower level of $\mathrm{FEV}_{1}$ and FVC. The associations 
were particularly strong in individuals with obesity. ${ }^{10}$ Long-term exposure to traffic and $\mathrm{PM}_{2.5}$ at relatively low levels was associated with lower $\mathrm{FEV}_{1}$ and FVC and an accelerated rate of decline in lung function. ${ }^{11}$ However, it remains unclear whether chronic exposure to ambient PM, especially for fine $\mathrm{PM}_{2.5}$ at high levels in China, is associated with COPD morbidity and lung function in adults, given that the complex composition and ambient concentrations of ambient PM vary greatly by country and region.

\section{METHODS}

\section{Study design and population}

The study population consisted of the participants in the National Science-Technology Support Plan Program for the 12th 5 -year plan, which was a population-based, cross-sectional, multicentre survey of COPD conducted in China (2012-2015). Eight clusters of districts/towns were randomly selected from four cities (ie, Guangzhou, Shaoguan, Heyuan and Zhanjiang) with different pollution levels well representative of Guangdong province. In each of these cities, we used a multistage cluster sampling strategy. Due to the large socioeconomic differences between rural and urban regions, we chose counties from Shaoguan, Heyuan as rural regions, and districts from Guangzhou, Zhanjiang as urban regions. Two districts or a rural county were randomly selected in each city, which was the first stage of the census tracts. As the second step of the sampling process, we randomly selected an urban street or two rural towns from each of the selected urban districts and rural counties (as air sampling cluster units). Two clusters of Shaoguan were combined because they were situated next to each other so that there remained seven sampling clusters in the study. Finally, we used a randomised cluster sampling algorithm to select urban communities or villages. The number of selected communities or villages depended on the size of the population in the participating clusters to meet the total sample size required for the design of this study. In the selected sample clusters, we then randomly recruited residents aged 20 years or older according to the latest census by local police stations where electronic registry data were maintained. The study protocol was approved by the institutional review board of each participating centre. All eligible local recruits in the selected clusters were invited to participate in the study with questionnaire and spirometry examinations. Eligible participants who missed our invited interview and/or spirometry received a home visit on a later occasion. COPD was diagnosed as a post-bronchodilator $\mathrm{FEV}_{1} / \mathrm{FVC}$ less than $70 \%$. Chest radiographs, ECG and blood pressure measurements were further examined to find contraindications and other disorders that may affect lung function.

\section{Spirometry}

Spirometry including pre-bronchodilator and postbronchodilator measurements was performed in all eligible participants to diagnose COPD by post-bronchodilator (Salbutamol Sulfate Aerosol, $400 \mu \mathrm{g}, 20 \mathrm{~min}$ later) $\mathrm{FEV}_{1} / \mathrm{FVC} \%$ of less than $70 \%$. Spirometric data were obtained using a portable spirometer (Carefusion MasterScreen Pneumo, Germany) interfaced for pulmonary function data acquisition and quality control software (Sentrysuite V.2.3) and calibrated daily. Spirometric manoeuvres were performed according to the European Respiratory Society/American Thoracic Society standards (ERS/ ATS 2005). ${ }^{12}$ As reported by Enright and colleagues, an A-F quality grade based on acceptable manoeuvres and repeatability of the $\mathrm{FEV}_{1}$ was used to evaluate spirometry results. ${ }^{13}$ Spirometry results with grades A, B or C were considered acceptable for analysis. All exams of spirometry were conducted within 1 month in the summer from 2012 through 2014.

\section{Questionnaire and risk factors for COPD}

A questionnaire interview was performed using a standardised questionnaire revised from the international BOLD (Burden of Obstructive Lung Diseases) study, including possible risk factors for COPD, such as family history of respiratory diseases, smoking status, occupational exposure, biomass fuel exposure and related medical history. Having a family history of respiratory diseases was identified by blood-related family members experiencing pulmonary diseases such as chronic bronchitis, asthma, emphysema, COPD, lung cancer, bronchiectasia and other heredity diseases that may affect the lung. A subject was referred to as a smoker if he/she had smoked more than five packs $\times$ year in his/her life. Exposure to high concentrations of all types of dust for more than 1 year without any protective measure was defined as occupational exposure. Biomass exposure was identified as use of biomass fuels for heat or warmth for more than 5 hours $\times$ year. Self-reported hospitalisation due to pneumonia more than once was considered as having a related medical history of pneumonia. Exposure to environmental tobacco smoke (ETS) was defined as having been exposed for at least 15 min daily for $>1$ day every week and for at least 2 years at home or in the workplace. ${ }^{14} \mathrm{~A}$ cumulative exposure index combined from home and work environments was identified as follows: the cumulative exposure at home (cigarettes/day $\times$ years) was classified into four categories (no exposure, 1-4 pack-years, 4-8 pack-years, $\geq 8$ pack-years) with scores ranging from 0 to 3 , respectively; cumulative exposure at work ((cigarettes/day $\times$ years $\times$ smokers $\times$ hours/day $/ 100$ ) was also classified into four categories (score 0 (ie, no exposure); score 1 (1-5); score 2 (5$15)$; score $3(\geq 15)$ ); total scores (ranging from 0 to 6 ) from cumulative exposure at home and work were classified into four levels (no exposure (ie, score 0), low exposure (score 1-2), moderate exposure (score 3-4), high exposure (score 5-6)). ${ }^{15}$ Participants with mothers who had a regular smoking and/or passive smoking history were also recorded. Other chronic pulmonary diseases were specifically defined as asthma, chronic bronchitis, TB, bronchiectasia, interstitial lung disease (ILD), allergic rhinitis and allergic sinusitis. COPD symptoms included one of the following symptoms lasting for more than 3 months and at least 2 years: dyspnoea, cough, sputum production, wheezing and chest tightness.

A total of 7098 participants were invited to participate in our study, among whom 1105 (15.57\%) were excluded due to missed or failed spirometry (including unacceptable spirometry) $(n=633)$, various unacceptable contraindications $(n=173)$, or incomplete questionnaires $(n=299)$, leading to a total of 5993 $(84.4 \%)$ study subjects included in our final analyses.

\section{Ambient particulate matter assessment}

We estimated the average air pollution exposure level using 1-year atmosphere PMs sampled in the participating clusters. $\mathrm{PM}_{2.5}$ and $\mathrm{PM}_{10}$ concentrations were measured using a portable ambient air sampler (Minivol Tactical Air Sampler, TAS, Air metrics Co., Springfield, Illinois, USA) in the heartland of every cluster, which was placed approximately $1000 \mathrm{~m}$ from the furthest street in participating urban areas, and approximately $3000 \mathrm{~m}$ for rural towns to estimate the background exposure in these regions. A standardised protocol was developed using identical equipment in each centre (Institute of Earth Environment; Chinese Academy of Sciences). The equipment contained a $47 \mathrm{~mm}$ filter holder (Air metrics Co.) for Whatman 
quartz microfiber filters (QM/A, Whatman Inc, UK), a Graseby-Andersen $\mathrm{PM}_{10}$ inlet, and a PQ100 pump (Air metrics Co.), with a cutoff size of 2.5 or $10 \mu \mathrm{m}$ aerodynamic diameter at a mini-volume flow rate of $5 \mathrm{~L} / \mathrm{min}$. Oil and filters were replaced after a maximum of 48 operating hours. Two samplers were assigned to each cluster to avoid measurement effect due to instrument damage. All the participants in one cluster were thus assigned to the same measurement of PM concentrations.

\section{Weighing procedure}

All pre-weighing and post-weighing of Whatman quartz microfiber filters were conducted in one central laboratory at the Institute of Earth Environment, Chinese Academy of Sciences, Xi'an by one senior technician. For the gravimetric analysis, a $1 \mu \mathrm{g}$ sensitivity microbalance (Sartorius, ME 5-F, Germany) with automatic data transfer to a personal computer was used. Before weighing, all filters were equilibrated in the temperature and humidity chamber for 24 hours at $20-23^{\circ} \mathrm{C}$ and $35-45 \%$ relative humidity to determine mass concentrations. Tweezers were used to handle the filters by the $4 \mathrm{~mm}$ rubber rim, and filters were numbered with a pen on this rim. Each blank filter was then pre-sintered on both sides for at least 3 hours in the muffle furnace (model 4-10, Shanghai test instrument factory) at a temperature of $780^{\circ} \mathrm{C}$ before weighing (to remove other organic pollutants). The pre-weighed filters were placed in a filter cassette in a plastic box (provided by Whatman Inc, UK) before they were sent to the field workers. Exposed filters were stored in a refrigerator at $4^{\circ} \mathrm{C}$ and were sent back in a single batch to the weighing laboratory at the end of the measuring period. The weighing procedure for the loaded filters was identical to that used for unloaded filters. The weighed filters were stored in a refrigerator at under $-4^{\circ} \mathrm{C}$. The weight variability was less than $15 \mu \mathrm{g}$ for unloaded filters and $20 \mu \mathrm{g}$ for loaded filters; three effective weighting results were saved for each filter. After exposure, filters were stored for a maximum of 10 days at room temperature before weighing. Otherwise, they were transferred to $4^{\circ} \mathrm{C}$ for a maximum of 30 days.

\section{PM sampling quality control procedure}

Every field worker must take 1-week professional training focused on equipment operation and atmosphere PM sampling. At least one field worker per centre was trained by the coordinating centre. Manuals and videos were developed to instruct non-experienced field workers to sample $\mathrm{PM}_{2.5}$ and $\mathrm{PM}_{10}$. Any deviation from the protocol during the sampling process was recorded.

\section{Measurement schedule}

Twenty-four hour air sampling was scheduled in every 3-day period for at least 10 days in a representative sampling month, except for rainy days. January, April, July and October represented the four typical seasons during a year in Guangdong, according to the Provincial Environment Protection Administration. It started in the early morning, and ended in the late morning, with deviations of less than $30 \mathrm{~min}$. Field blank filters were collected at each site. The weight difference of sampling filters before and after sampling was calculated by subtracting the field blank filter to obtain the net weight for each sample. At least 10 eligible filter samples were collected in every month by one sampler (supplementary measurements were conducted in the days immediately following in case one was missed) which represented 10-day measurements. From these 10 samples, a monthly mean concentration and a seasonal mean concentration was calculated. Thus, 'yearly mean concentration' was defined as the average of the four seasons. Our sampling process for all the centres began in April 2014 and ended in January 2015. table 1 shows the ambient air quality standards for $\mathrm{PM}_{10}$ and $\mathrm{PM}_{2.5}$ : the average concentration limits for a 24 hour period. A measurement higher than the second level indicates the state of pollution.

\section{Statistical analyses}

We first performed logistic regression analyses to examine the associations between exposure variables (ie, $\mathrm{PM}_{2.5}$ and $\mathrm{PM}_{10}$ ) and COPD prevalence, COPD-related symptoms and other chronic pulmonary diseases. Then, we conducted further analyses to associate PM concentrations with lung function outcomes using multiple linear regression models. All logistic regression analyses were adjusted for age, sex, personal education state, smoking history, family history, biofuel and occupational exposure, history of childhood pneumonia in hospital, mother's smoking during pregnancy, maternal exposure to second-hand smoking during pregnancy, kitchen ventilation quality, second-hand smoking exposure, urban/rural distribution and clusters. $\mathrm{PM}_{2.5 / 10}$ was used as a categorised variable to fit logistic regression models. Before performing multiple linear regression models, simple linear regression models were used to screen effective variables for lung function. Thus, covariates such as mother's smoking during pregnancy, maternal exposure to second-hand smoking during pregnancy, kitchen ventilation quality, second-hand smoking exposure were all excluded from the models with spirometry outcomes as dependent variables. Age, smoking pack $\times$ years, biofuel index and PM concentration were used as continuous variable. Models with spirometry outcomes were also adjusted for height and weight. Information on all covariates in the final analyses was almost complete because telephone calls were made to capture missing data. A variable value of approximately $0.2 \%$ was used for missing values based on the variables of other subjects. All analyses were performed using IBM SPSS V.19.0.

\section{RESULTS}

The characteristics of study participants are summarised in table 2. Older age, male sex, lower levels of education, smoking, occupational or biomass exposure, family members with related respiratory disease, a history of cough or hospitalisation for pneumonia in childhood appeared to be associated with higher COPD prevalence. The effects related to kitchen ventilation quality and ETS were weak or absent (table 2).

The seasonal mean $\mathrm{PM}_{2.5} / 10$ mass concentrations from April 2014 to January 2015 for the seven centres are shown in online supplementary figure S1. The outdoor PM $\left(\mathrm{PM}_{10} / 2.5\right)$ varied greatly by season, region and day. These concentrations were clearly lower in summer but apparently higher in winter. There were lowest year-round average daily concentrations of approximately $22.72 \pm 8.58 \mu \mathrm{g} / \mathrm{m}^{3}$ in Donghai Island, but the highest daily concentrations of up to $75.37 \pm 26.6 \mu \mathrm{g} / \mathrm{m}^{3}$ for $\mathrm{PM}_{2.5}$ in Liwan

Table 1 Ambient air quality standards

\begin{tabular}{|c|c|c|c|c|}
\hline \multirow[b]{2}{*}{ PM } & \multirow[b]{2}{*}{ Average time (hours) } & \multicolumn{2}{|c|}{ Concentration limit } & \multirow[b]{2}{*}{ Unit } \\
\hline & & First level & Second level & \\
\hline $\mathrm{PM}_{10}$ & 24 & 50 & 150 & $\mu \mathrm{g} / \mathrm{m}^{3}$ \\
\hline $\mathrm{PM}_{2.5}$ & 24 & 35 & 75 & \\
\hline
\end{tabular}

Standards are from China national standard 2012 (GB 3095-2012). 
Table 2 Characteristics of all study participants

\begin{tabular}{|c|c|c|c|}
\hline & $\mathrm{N}$ or mean (SD) & COPD (N) & Prevalence (\%) \\
\hline \multicolumn{4}{|l|}{ Age group, year } \\
\hline$\leq 40$ & 1318 & 9 & 0.68 \\
\hline $41-60$ & 3254 & 188 & 5.78 \\
\hline$>60$ & 1421 & 324 & 22.80 \\
\hline \multicolumn{4}{|l|}{ Sex } \\
\hline Male & 2959 & 397 & 13.42 \\
\hline Female & 3034 & 124 & 4.09 \\
\hline \multicolumn{4}{|l|}{ Education status } \\
\hline Under primary school & 423 & 48 & 11.34 \\
\hline Primary school & 1557 & 181 & 11.62 \\
\hline Junior high school & 2022 & 193 & 9.55 \\
\hline Senior high school & 1405 & 78 & 5.55 \\
\hline Graduate and above & 586 & 21 & 3.75 \\
\hline \multicolumn{4}{|l|}{ Smoking history } \\
\hline Yes & 2039 & 346 & 16.96 \\
\hline No & 3954 & 175 & 4.42 \\
\hline \multicolumn{4}{|l|}{ Occupational exposure } \\
\hline Yes & 2419 & 291 & 12.03 \\
\hline No & 3574 & 230 & 6.44 \\
\hline \multicolumn{4}{|l|}{ Biofuel exposure } \\
\hline Yes & 2477 & 254 & 10.25 \\
\hline No & 3516 & 267 & 7.59 \\
\hline \multicolumn{4}{|l|}{ Family history } \\
\hline Yes & 469 & 59 & 12.58 \\
\hline No & 5524 & 462 & 8.36 \\
\hline \multicolumn{4}{|c|}{ History of childhood pneumonia in the hospital } \\
\hline Yes & 125 & 22 & 17.60 \\
\hline No & 5868 & 499 & 8.50 \\
\hline \multicolumn{4}{|c|}{ Mother smoking during pregnancy } \\
\hline Yes & 277 & 32 & 11.55 \\
\hline No & 5716 & 489 & 8.55 \\
\hline \multicolumn{4}{|c|}{ Mother exposed to second-hand smoking during pregnancy } \\
\hline Yes & 3008 & 265 & 8.81 \\
\hline No & 2985 & 256 & 8.58 \\
\hline \multicolumn{4}{|l|}{ Kitchen ventilation quality } \\
\hline $\mathrm{Bad}$ & 3286 & 296 & 9.01 \\
\hline Common & 2212 & 188 & 8.50 \\
\hline Good & 495 & 37 & 7.47 \\
\hline \multicolumn{4}{|c|}{ Environmental tobacco smoking exposure* } \\
\hline 0 & 3741 & 356 & 9.52 \\
\hline 1 & 1090 & 104 & 9.54 \\
\hline 2 & 1155 & 60 & 5.19 \\
\hline 3 & 7 & 1 & 14.29 \\
\hline \multicolumn{4}{|c|}{ Rural and urban distribution } \\
\hline Rural & 3800 & 378 & 9.95 \\
\hline Urban & 2193 & 143 & 6.52 \\
\hline \multicolumn{4}{|l|}{ Lung function outcomes } \\
\hline $\mathrm{FEV}_{1}, \mathrm{~L}$ & $2.61(0.7)$ & - & - \\
\hline FVC, L & $3.21(0.8)$ & - & - \\
\hline $\mathrm{FEV}_{1} \%$ pred, $\%$ & $97.63(16.2)$ & - & - \\
\hline FVC\%pred, \% & 99.59 (15.5) & - & - \\
\hline $\mathrm{FEV}_{1} / \mathrm{FVC}, \%$ & $81.45(9.7)$ & - & - \\
\hline
\end{tabular}

District (figure 1). The day-to-day variability was large in Liwan and Yuexiu, while it was small in Donghai Island. In general, clusters with low PM mass concentrations had less daily variability than centres with high concentrations during the 4 months. ${ }^{16}$
The adjusted prevalence rates of COPD among participants aged $\geq 20$ years in the sampling clusters were within a range from $5.1 \%$ to $11.1 \%$ (ie, from $3.1 \%$ to $4.9 \%$ for women; from $5.2 \%$ to $18.1 \%$ for men), with the highest prevalence in Wengyuan Zhoupi town (11.1\%) and the lowest in Xiashan District $(5.1 \%)$ (table 3 ). There was considerable difference between clusters in year-round daily mean PM (figure 1). However, we did not observe statistically significant effect modifications of the associations between year-round mean daily PM concentrations and COPD prevalence using correlation analysis (see online supplementary table S5), and consistent results were observed for male and female participants (see online supplementary table S5 and figure S2).

Logistic regression models were then used to further examine the association between year-round daily mean PM concentration and COPD after adjusting for available confounding factors. As shown in table 4, higher year-round daily mean $\mathrm{PM}_{2.5}$ concentrations were likely associated with COPD prevalence, with adjusted OR 2.416 (95\% CI 1.417 to 4.118 ) for $>30$ and $\leq 75 \mu \mathrm{g} / \mathrm{m}^{3}$ and 2.530 (95\% CI 1.280 to 5.001) for $>75 \mu \mathrm{g} / \mathrm{m}^{3}$, respectively compared with the lower limit level of $\leq 35 \mu \mathrm{g} / \mathrm{m}^{3}$. Increased $\mathrm{PM}_{10}$ pollution level appeared to be significantly harmful to respiratory health (eg, COPD) with an adjusted OR of 2.442 (95\% CI 1.449 to 4.117$)$ for $>50$ and $\leq 150 \mu \mathrm{g} / \mathrm{m}^{3}$ versus the level for $\leq 50 \mu \mathrm{g} / \mathrm{m}^{3}$. Participants from areas with high levels of $\mathrm{PM}_{2.5} / 10$ were at higher risk of having chronic cough, dyspnoea, sputum production, wheezing or chest tightness than those from areas with low levels. They also had elevated risks of other chronic respiratory diseases such as asthma, chronic bronchitis, TB, bronchiectasia, ILD, allergic rhinitis and allergic sinusitis (table 4). All analyses were adjusted for age, sex, personal education state, smoking history, family history, biofuel and occupational exposure, history of childhood pneumonia in the hospital, mother's smoking during pregnancy, maternal exposure to second-hand smoking during pregnancy, kitchen ventilation quality, second-hand smoking exposure, urban/rural distribution and clusters. Meanwhile, the effect of air pollution on COPD prevalence, COPD symptoms and other pulmonary diseases appeared to be statistically significant for men and smokers, but not for women and non-smokers (see online supplementary tables S1-4).

In our multiple regression analysis, we found a linear correlation between ambient year-round daily mean PM concentrations and lung function (table 5). An increased concentration of $10 \mu \mathrm{g} / \mathrm{m}^{3}$ in $\mathrm{PM}_{2.5}$ was associated with a decline of $26 \mathrm{~mL}$ (95\% CI -43 to -9$)$ in $\mathrm{FEV}_{1}$, a decline of $28 \mathrm{~mL} \mathrm{(95 \%} \mathrm{CI}-49$ to -8$)$ in $\mathrm{FVC}$, and a $0.09 \%$ (95\% CI -0.170 to -0.010 ) decline in $\mathrm{FEV}_{1} / \mathrm{FVC}$ ratio. Associations for $\mathrm{PM}_{10}$ were $14 \mathrm{~mL}$ (95\% CI -22 to -6$)$ lower in $\mathrm{FEV}_{1}, 16 \mathrm{~mL}(95 \% \mathrm{CI}-28$ to -4) lower in FVC and $0.024 \%$ (95\% CI -0.092 to 0.040$)$ lower in $\mathrm{FEV}_{1} / \mathrm{FVC}$ ratio, a little weaker than $\mathrm{PM}_{2.5}$. All linear regression analyses were adjusted for sex, age, height, weight, smoking pack-year, education level, family history, biofuel (hours $\times$ year), occupational exposure, history of childhood pneumonia in hospital, urban/rural distribution and clusters.

\section{DISCUSSION}

Despite great improvement in ambient air quality over the past 30 years, air pollution continues to impose a challenge to regulatory and health professionals in most countries around the world. In this cross-sectional study, we found that increased PM concentrations are significantly associated with increased COPD prevalence and decreased respiratory function in Guangdong, China. We also found that the increased daily mean $\mathrm{PM}_{2.5}$ and 
A The year-round daily mean PM 2.5 concentration and COPD prevalence in the 7 clusters

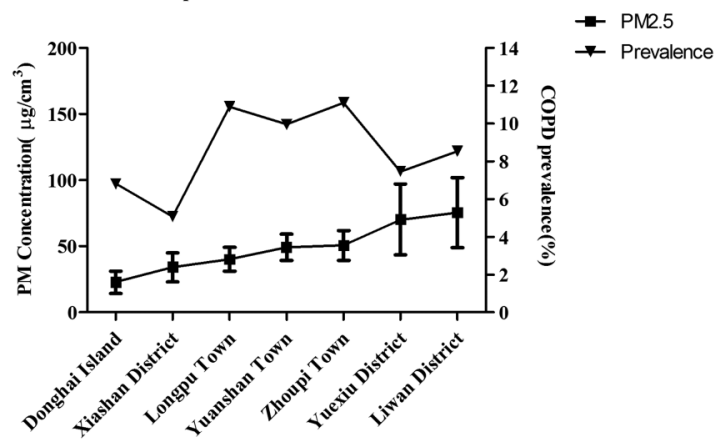

B The year-round daily mean PM ${ }_{10}$ concentration and COPD prevalence in the 7 clusters

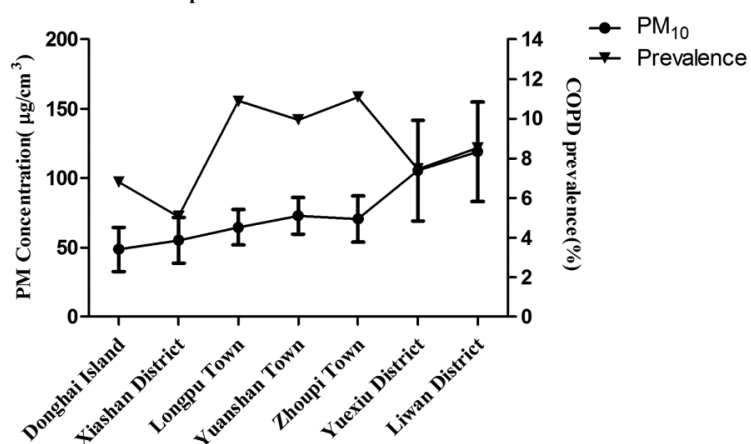

Figure 1 The year-round daily mean particulate matter concentrations and COPD prevalence in seven clusters. Year-round daily mean $\mathrm{PM}_{2.5} / 10$ concentrations were calculated using data collected from April 2014 to January 2015 at the seven monitoring stations; values are shown as mean and SD; $\mathrm{PM}_{2.5} /{ }_{10}=$ particulate matter with a median aerodynamic diameter $<2.5 / 10 \mu \mathrm{m}$.

Table 3 COPD prevalence (\%) and $95 \% \mathrm{Cl}$ in each cluster

\begin{tabular}{|c|c|c|c|c|c|c|c|c|}
\hline \multirow[b]{2}{*}{ Clusters } & \multirow[b]{2}{*}{ N } & \multirow[b]{2}{*}{$\begin{array}{l}\text { Mean age (SD), } \\
\text { years }\end{array}$} & \multirow[b]{2}{*}{$\begin{array}{l}\text { Prevalence \% } \\
(95 \% \mathrm{Cl})\end{array}$} & \multirow[b]{2}{*}{$\begin{array}{l}\text { Adjusted } \\
\text { prevalence } \% \\
(95 \% \mathrm{Cl})\end{array}$} & \multicolumn{2}{|l|}{ Male } & \multicolumn{2}{|l|}{ Female } \\
\hline & & & & & $\mathrm{N}(\%)$ & $\begin{array}{l}\text { Adjusted } \\
\text { prevalence \% } \\
(95 \% \mathrm{Cl})\end{array}$ & N (\%) & $\begin{array}{l}\text { Adjusted } \\
\text { prevalence \% } \\
(95 \% \mathrm{Cl})\end{array}$ \\
\hline Donghai Island & 718 & $48.1(13.0)$ & 5.5 (3.9 to 7.2$)$ & 6.8 (5.0 to 8.6$)$ & $344(47.9)$ & 8.6 (5.6 to 11.5$)$ & 374 (52.1) & 4.9 (3.2 to 6.6$)$ \\
\hline Xiashan District & 782 & $49.1(12.8)$ & 4.1 (2.7 to 5.5$)$ & 5.1 (3.5 to 6.6 ) & $368(47.1)$ & 5.6 (3.5 to 7.7$)$ & $414(52.9)$ & 4.5 (2.8 to 6.1$)$ \\
\hline Longpu Town & 594 & $51.1(12.7)$ & 11.1 (8.6 to 13.6 ) & 10.9 (8.4 to 13.4$)$ & $306(51.5)$ & 16.6 (11.8 to 21.3$)$ & $288(48.5)$ & 4.7 (3.2 to 6.2$)$ \\
\hline Yuanshan Town & 887 & $49.1(12.5)$ & 10.0 (8.1 to 12.0$)$ & 10.0 (8.0 to 11.9$)$ & 440 (49.6) & 16.2 (10.5 to 21.9$)$ & $447(50.4)$ & 3.2 (1.9 to 4.4$)$ \\
\hline Zhoupi Town* & 1601 & $51.0(123)$ & 11.5 (9.9 to 13.0$)$ & 11.1 (9.6 to 12.6$)$ & $816(51.0)$ & 16.8 (8.9 to 24.7 ) & $785(49.0)$ & 4.9 (2.4 to 7.4$)$ \\
\hline Yuexiu District & 648 & $52.1(13.4)$ & 7.6 (5.5 to 9.6 ) & 7.5 (6.6 to 10.5$)$ & 315 (48.6) & 10.8 (7.3 to 14.3$)$ & 333 (51.4) & 3.8 (2.6 to 5.1$)$ \\
\hline Liwan District & 763 & 50.9 (13.4) & $8.1(6.2$ to 10.1$)$ & 8.5 (6.6 to 10.5$)$ & $370(48.5)$ & 12.5 (8.2 to 16.8 ) & 393 (51.5) & 4.2 (2.7 to 5.8 ) \\
\hline Total & 5993 & $50.2(12.9)$ & 8.7 (8.0 to 9.4$)$ & 8.9 (8.2 to 9.6$)$ & 2959 (49.4) & 13.0 (11.9 to 14.2$)$ & $3034(50.6)$ & 4.4 (3.6 to 5.1$)$ \\
\hline
\end{tabular}

*Zhoupi Town includes Jiangwei Town, because the two towns are quite close.

$\mathrm{PM}_{10}$ levels were associated with an increased risk of COPD symptoms and other chronic pulmonary diseases.

To our knowledge, this is one of the few studies to explore associations between chronic atmospheric PM exposure and COPD. Some studies have reported stronger associations between acute exacerbation, hospitalisation, mortality of COPD and acute exposure to elevated $\mathrm{PM}_{2.5}$ concentration. ${ }^{17}{ }^{18} \mathrm{~A}$ stratified analysis revealed significant associations for non-Hispanic black people (OR 1.73, 95\% CI 1.17 to 2.56 for current asthma and OR 1.76, 95\% CI 1.07 to 2.91 for recent attacks) with a $10 \mu \mathrm{g} / \mathrm{m}^{3}$ increase in $\mathrm{PM}_{2.5} \cdot{ }^{9}$ A more recent study assessed the relative risk of hospital admissions for respiratory diseases with short-term effects of $\mathrm{PM}_{2.5}$ using a casecrossover approach, controlling for weather variables, day of the week, seasonality and chronic time trends. The results provided evidence that higher levels of $\mathrm{PM}_{2.5}$ increased the risk of hospital admissions for respiratory diseases in Taiwan. ${ }^{19}$ In addition, a number of studies confirmed daily short-term elevated atmospheric $\mathrm{PM}_{2.5}$ concentrations can cause respiratory damage, including COPD symptoms and acute admission rates. ${ }^{3} 1820$ There were detrimental respiratory and pulmonary effects observed in response to even low levels of ambient air pollutants among study participants, indicating that exposures even below those of air quality standards may still pose significant risks to patients with severe COPD. ${ }^{21}$ Decreased rates of death from emphysema, asthma and pneumonia were observed when levels of ambient air pollutants were improved. ${ }^{22} 23$
In China, $\mathrm{PM}_{2.5} / \mathrm{PM}_{10}$ is not routinely monitored in most regions, especially in spacious rural area. We measured mass concentrations of $\mathrm{PM}_{2.5}$ and $\mathrm{PM}_{10}$ using a provisional atmosphere PM sampler to estimate the average exposure level of sample clusters. We did not find statistically significant effect modifications of the associations between year-round mean daily PM concentrations and COPD prevalence using a simple linear regression model. Similar results were also observed in men and women. However, a substantial body of evidence has shown that COPD is not a single-cause disease but is associated with multiple risk factors. ${ }^{24-24}$ It is well known that cigarette smoking is the primary cause of COPD and it is more prevalent in rural areas. ${ }^{27-29}$ In contrast, the impact of outdoor fine PM might be less significant. Given our limited number of sample clusters, it is very difficult to define their complex relationship. Therefore, we used a logistic regression to examine the relationship between daily mean PM concentration and COPD after adjusting for major confounding factors such as age, smoking, occupational and biofuel exposures and clusters. PM concentrations from the seven monitoring points were divided into three levels for $\mathrm{PM}_{2.5}$ and two for $\mathrm{PM}_{10}$, according to the recommendations of the National Environmental Protection Department concerning PM pollution (see Methods). There was one location with $\mathrm{PM}_{2.5}$ concentrations higher than $75 \mu \mathrm{g} / \mathrm{m}^{3}$ in this study. We found that increases in daily mean $\mathrm{PM}_{2.5}$ concentrations are associated with COPD prevalence. Similar strong evidence was also found for the association between the increase in daily 
Table 4 Ambient air particulate matter levels and hazards for COPD and other pulmonary outcomes

\begin{tabular}{|c|c|c|c|c|c|c|}
\hline \multirow[b]{3}{*}{ PM levels } & \multirow{2}{*}{\multicolumn{2}{|c|}{$\begin{array}{l}\text { COPD } \\
\mathrm{N}=521\end{array}$}} & \multirow{2}{*}{\multicolumn{2}{|c|}{$\begin{array}{l}\text { COPD symptoms } \\
\mathrm{N}=1283\end{array}$}} & \multirow{2}{*}{\multicolumn{2}{|c|}{$\begin{array}{l}\text { Other chronic pulmonary diseases } \\
\mathrm{N}=696\end{array}$}} \\
\hline & & & & & & \\
\hline & Adjusted OR* & $95 \% \mathrm{Cl}$ & Adjusted OR & $95 \% \mathrm{Cl}$ & Adjusted OR & $95 \% \mathrm{Cl}$ \\
\hline \multicolumn{7}{|l|}{$\mathrm{PM}_{2.5}$} \\
\hline$\leq 35 \mu \mathrm{g} / \mathrm{m}^{3}$ & 1 & reference & 1 & reference & 1 & reference \\
\hline$>35$ and $\leq 75 \mu \mathrm{g} / \mathrm{m}^{3}$ & 2.416 & 1.417 to 4.118 & 1.458 & 1.132 to 1.879 & 1.836 & 1.245 to 2.708 \\
\hline$>75 \mu \mathrm{g} / \mathrm{m}^{3}$ & 2.530 & 1.280 to 5.001 & 1.285 & 0.888 to 1.859 & 1.870 & 1.142 to 3.062 \\
\hline \multicolumn{7}{|l|}{$\mathrm{PM}_{10}$} \\
\hline$\leq 50 \mu \mathrm{g} / \mathrm{m}^{3}$ & 1 & reference & 1 & reference & 1 & reference \\
\hline$>50$ and $\leq 150 \mu \mathrm{g} / \mathrm{m}^{3}$ & 2.442 & 1.449 to 4.117 & 1.448 & 1.129 to 1.858 & 1.900 & 1.291 to 2.797 \\
\hline
\end{tabular}

Table 5 Ambient air particulate matter exposure and effects on lung function

\begin{tabular}{|c|c|c|c|c|c|c|}
\hline \multirow[b]{2}{*}{ Lung function outcome } & \multicolumn{3}{|c|}{ Daily mean $\mathrm{PM}_{2.5}$ concentration $\left(10 \mu \mathrm{g} / \mathrm{m}^{3}\right)$} & \multicolumn{3}{|c|}{ Daily mean $\mathrm{PM}_{10}$ concentration $\left(10 \mu \mathrm{g} / \mathrm{m}^{3}\right)$} \\
\hline & B & $95 \% \mathrm{Cl}$ & $\mathrm{p}$ Value & B & $95 \% \mathrm{Cl}$ & $p$ Value \\
\hline $\mathrm{FEV}_{1}(\mathrm{~mL})$ & -26 & $(-43$ to -9$)$ & 0.01 & -14 & $(-22$ to -6$)$ & 0.01 \\
\hline $\mathrm{FVC}(\mathrm{mL})$ & -28 & $(-49$ to -8$)$ & 0.007 & -16 & $(-28$ to -4$)$ & 0.007 \\
\hline $\mathrm{FEV}_{1} \%$ pred (\%) & -0.96 & $(-1.646$ to -0.274$)$ & 0.014 & -0.535 & $(-0.952$ to -0.118$)$ & 0.014 \\
\hline FVC\%pred (\%) & -0.852 & $(-1.490$ to -0.213$)$ & 0.009 & -0.495 & $(-0.866$ to -0.124$)$ & 0.009 \\
\hline $\mathrm{FEV}_{1} / \mathrm{FVC}(\%)$ & -0.09 & $(-0.170$ to -0.010$)$ & 0.027 & -0.024 & $(-0.092$ to 0.040$)$ & 0.489 \\
\hline
\end{tabular}

$\mathrm{B}=$ regression coefficient of daily mean $\mathrm{PM}_{2.5} /{ }_{10}$ concentration for lung function adjusted for sex, age, height, weight, smoking pack-years, education state, family history, biofuel (hoursxyear), occupational exposure, history of childhood pneumonia in the hospital, rural and urban distribution, clusters; $\mathrm{PM}_{2.5} / 10=$ particulate matter with a median aerodynamic diameter $<2.5 / 10 \mu \mathrm{m}$. Data calculation was based on all 5993 participants in the seven clusters.

mean $\mathrm{PM}_{10}$ concentration level and COPD prevalence. A few studies have reported associations between COPD prevalence and exposure to elevated $\mathrm{PM}_{2.5}$ concentration. ${ }^{30}$ As reported in a recent study, a $7 \mu \mathrm{g} / \mathrm{m}^{3}$ increase in the 5-year mean $\mathrm{PM}_{10}$ (IQR) was associated with an OR of 1.33 (95\% CI 1.03 to 1.72) for COPD. ${ }^{31}$ Unexpectedly, the ORs of $\mathrm{PM}_{2.5}$ at levels $>35$ but $<75 \mu \mathrm{g} / \mathrm{m}^{3}$ and $\mathrm{PM}_{10}$ at levels $>50$ but $<150 \mu \mathrm{g} / \mathrm{m}^{3}$ were found to be close. In addition, the ORs of $\mathrm{PM}_{2.5}$ at levels $>75 \mu \mathrm{g} / \mathrm{m}^{3}$ were not much higher than those at levels $>35$ but $<75 \mu \mathrm{g} / \mathrm{m}^{3}$. The distinct differential effect might not be detected because $\mathrm{PM}_{2.5}$ concentrations $>75 \mu \mathrm{g} / \mathrm{m}^{3}$ were only observed in one location in our survey $\left(75.4 \mu \mathrm{g} / \mathrm{m}^{3}\right)$. This may also explain why we set the cutoff value of $150 \mu \mathrm{g} / \mathrm{m}^{3}$ as an upper limit of the second level for $\mathrm{PM}_{10}$ and $75 \mu \mathrm{g} / \mathrm{m}^{3}$ for $\mathrm{PM}_{2.5}$. Another reason may be that the adverse impact of PM on COPD is increasingly nonlinear, but in an ' $\mathrm{S}$ ' or other pattern. Meanwhile, we found the effect of PM on COPD prevalence appeared to be statistically significant for men and smokers, though not for women and non-smokers (see online supplementary tables S1-4). It is well known that COPD prevalence is relatively low in non-smokers and women, which indicates that numerous investigation clusters are needed to discover the impact of PM on COPD. Given the complex composition of $\mathrm{PM}$, it is difficult to define its true relationship with outcomes of interest.

A recent study showed that each $2 \mu \mathrm{g} / \mathrm{m}^{3}$ increase in the average $\mathrm{PM}_{2.5}$ was associated with a $13.5 \mathrm{~mL}(95 \% \mathrm{CI}-26.6$ to -0.3) lower $\mathrm{FEV}_{1}$ and a $2.1 \mathrm{~mL} /$ year $(95 \% \mathrm{CI}-4.1$ to -0.2 ) decline in $\mathrm{FEV}_{1}$; there were similar associations with $\mathrm{FVC}$ after long-term exposure to traffic emissions. ${ }^{11}$ Each $2 \mu \mathrm{g} / \mathrm{m}^{3}$ increment in prior year $\mathrm{PM}_{2.5}$ was associated with lower FVC $(-21.8 \mathrm{~mL} ;-43.9$ to 0.2$)$ and higher odds of $\mathrm{FEV}_{1}<80 \%$ predicted $(1.41 ; 1.03$ to 1.93$)$ in children. ${ }^{32}$ Another study showed that each $10 \mu \mathrm{g} / \mathrm{m}^{3}$ increase in the average $\mathrm{PM}_{2.5}$ was associated with a 0.09-1.5 decline in $\mathrm{FEV}_{1} \%$ predicted ${ }^{21}$ These effects of lung function damage were relatively higher than those in our study. The reasons may be due to large composition and ratio differences between traffic $\mathrm{PM}_{2.5}$ and atmospheric $\mathrm{PM}_{2.5}$, and the population's sensitivity to pollutants. Exposure to highly mixed atmospheric pollutant PM may cause less damage to lung function than pure traffic-related PM. ${ }^{33}$ In addition, our study obtained only seven sample data points in Guangdong, a large province of southern China where air pollution is relatively light and has been substantially improved in recent years. ${ }^{34}$ These may in part explain why the effect we observed was smaller than that reported by other researchers. We found an increased concentration of $10 \mu \mathrm{g} / \mathrm{m}^{3}$ in $\mathrm{PM}_{2.5}$ was associated with the decrease in $\mathrm{FEV}_{1}$ and FVC. The decrease in $\mathrm{FEV}_{1}$ was about the same or even more serious than that for FVC, with the decrease in $\mathrm{FEV}_{1} \%$ predicted a little higher than FVC \% predicted. Thus it could be plausible for some long-term PM exposed individuals to develop COPD. However, associations for $\mathrm{PM}_{10}$ were weaker than those for $\mathrm{PM}_{2.5}$, and no clear significance for $\mathrm{FEV}_{1} / \mathrm{FVC}$ decline was observed. The Normative Aging Study of elderly men recently found that long-term estimates of exposure to black carbon, a traffic-related constituent of PM weighted towards diesel, were associated with accelerated decline in $\mathrm{FEV}_{1}$ and FVC. ${ }^{35}$ This study showed that the cross-sectional effect of black carbon exposure on baseline lung function was slightly stronger for $\mathrm{FEV}_{1}$ than for $\mathrm{FVC}$, suggesting an obstructive 
effect. However, the longitudinal effect of black carbon on lung function decline was stronger for FVC compared with $\mathrm{FEV}_{1}$, a restrictive pattern. The ESCAPE meta-analysis found nonsignificant positive associations between long-term estimates of $\mathrm{PM}_{10}$ and odds of COPD (defined as $\mathrm{FEV}_{1} / \mathrm{FVC}$ of 0.7 ), suggesting a possible obstructive effect. ${ }^{36}$

However, we did not find clear associations between air PM exposures and lung function in participants with COPD (see online supplementary table S6). The results of Lagorio's study suggested that the short-term negative impact of exposure to air pollutants on respiratory volume and flow is limited to individuals with impaired respiratory function. ${ }^{5}$ The fine fraction of ambient PM seems responsible for the observed effects among COPD cases, with zinc and iron having a potential role via oxidative stress. The respiratory function of the relatively young and people with mild asthma included in his study seemed to worsen when ambient levels of $\mathrm{NO}_{2}$ increased. ${ }^{5}$ Differences in the source, composition and proportion of pollutants might also cause the differences in our results. In addition, insufficient numbers of sampling points may have biased the results.

Small sample size of clusters and the 1-year sampling time span are among the limitations in this study. However, they did not affect our conclusion because there have been no significant changes in industry, traffic and urbanisation construction in recent years and there have been stable levels of PM concentration in these areas for the past several years. ${ }^{34} 37$ The yearround daily mean PM concentration could be slightly on the high side relative to daily real-time monitoring concentrations published by official agencies since the PM sampling was conducted on non-rainy days. Thus, we used the ambient air quality standards for $\mathrm{PM}_{10}$ and $\mathrm{PM}_{2.5}$ with average concentration limits over 24 hours, not the yearly values. However, all the sampling and filter weighting processes were completed under the strict guidance of the environment protection department. The effect of the weather on each sampling point was quite consistent because the daily sampling proceeded almost synchronously and was restricted in Guangdong province. Another limitation is that our random sampling investigation might not have taken into account the possibility that participants moved to areas with more or less air pollution due to socioeconomic reasons. Nevertheless, migration, if any, might affect a limited number of individuals but not a large population. Moreover, subjects invited to participate were from the local registered population and had lived there for a long time when our investigation took place; in addition, the four cities in our study were located a long way from each other. These facts make such a migration effect less likely to play a role.

In conclusion, we have revealed that increased daily mean PM concentration is associated with higher COPD prevalence and lower lung function in a Chinese population with a relatively high level of ambient PM in southern China. More importantly, air pollution continues to impose a challenge to regulatory and health professionals in most countries around the world. Further research is needed to clarify the differential susceptibility to these pollutants and individual exposure differences, and to explore possible pathogenic mechanisms of COPD triggered by air PM.

\footnotetext{
Author affiliations

${ }^{1}$ The State Key Laboratory of Respiratory Disease, Guangzhou Institute of Respiratory Disease, The First Affiliated Hospital, Guangzhou Medical University, Guangzhou, Guangdong, China

${ }^{2}$ Institute of Earth Environment, Chinese Academy of Sciences, Xi'an, China

${ }^{3}$ Department of Pathogenic Biology, Guangzhou Medical University, Guangzhou, China

${ }^{4}$ Guangzhou Chest Hospital, Guangzhou, Guangdong, China
}

${ }^{5}$ The Research Center of Experimental Medicine, Guangzhou Medical University, Guangzhou, Guangdong, China

${ }^{6}$ The Third Affiliated Hospital, Guangzhou Medical University, Guangzhou, Guangdong, China

${ }^{7}$ School of Epidemiology, Public Health and Preventive Medicine, University of Ottawa, Ottawa ON, Canada

Correction notice This article has been corrected since it was published Online First. The Ethics statement has been corrected from "Ethical Society in Guangdong province." to "Medical Ethics Committee of The First Affiliated Hospital, Guangzhou Medical University".

Contributors Conceived and designed the experiments: PR; experiments: SL, YZ, WZ, DZ, XL, JP, LH, JC, BL; PM2.5 and PM10 concentrations measured and weighed: SL, SL; data collection: SL, XC; data analysis: SL, SL, YZ; wrote the first draft of the manuscript: SL, PR; contributed to writing the manuscript: SL, PR, SL, YZ, BL.

Funding The study was funded by Chinese central government key research projects of the 12th national five-year development plan grant no. 2012BAI05B01 (to PR), the National Natural Science Foundation of China grant no. 81170043 and 81470233 (to PR), and National Key Basic Research and Development Programme, 973 Program, no. 2015 CB553403 (to YZ).

Competing interests None declared.

\section{Patient consent Obtained.}

Ethics approval Medical Ethics Committee of The First Affiliated Hospital, Guangzhou Medical University.

Provenance and peer review Not commissioned; externally peer reviewed.

Open Access This is an Open Access article distributed in accordance with the Creative Commons Attribution Non Commercial (CC BY-NC 4.0) license, which permits others to distribute, remix, adapt, build upon this work non-commercially, and license their derivative works on different terms, provided the original work is properly cited and the use is non-commercial. See: http://creativecommons.org/ licenses/by-nc/4.0/

\section{REFERENCES}

1 Wright RJ, Brunst KJ. Programming of respiratory health in childhood: influence of outdoor air pollution. Curr Opin Pediatr 2013;25:232-9.

2 Peters JM, Avol E, Navidi W, et al. A study of twelve Southern California communities with differing levels and types of air pollution. I. Prevalence of respiratory morbidity. Am J Respir Crit Care Med 1999;159:760-7.

3 Schwartz J. Short term fluctuations in air pollution and hospital admissions of the elderly for respiratory disease. Thorax 1995;50:531-8.

4 Atkinson RW, Anderson HR, Sunyer J, et al. Acute effects of particulate air pollution on respiratory admissions: results from APHEA 2 project. Air Pollution and Health: a European Approach. Am J Respir Crit Care Med 2001;164:1860-6.

5 Lagorio S, Forastiere F, Pistelli R, et al. Air pollution and lung function among susceptible adult subjects: a panel study. Environ Health 2006;5:11.

6 Peacock JL, Anderson HR, Bremner SA, et al. Outdoor air pollution and respiratory health in patients with COPD. Thorax 2011;66:591-6.

7 Rice MB, Ljungman PL, Wilker EH, et al. Short-term exposure to air pollution and lung function in the Framingham Heart Study. Am J Respir Crit Care Med 2013:188:1351-7.

8 Peel JL, Tolbert PE, Klein $M$, et al. Ambient air pollution and respiratory emergency department visits. Epidemiology 2005;16:164-74.

9 Nachman KE, Parker JD. Exposures to fine particulate air pollution and respiratory outcomes in adults using two national datasets: a cross-sectional study. Environ Health 2012;11:25

10 Adam M, Schikowski T, Carsin AE, et al. Adult lung function and long-term air pollution exposure. ESCAPE: a multicentre cohort study and meta-analysis. Eur Respir J 2015;45:38-50.

11 Rice $M B$, Ljungman $\mathrm{PL}$, Wilker $\mathrm{EH}$, et al. Long-term exposure to traffic emissions and fine particulate matter and lung function decline in the Framingham Heart Study. Am J Respir Crit Care Med 2015;191:656-64.

12 Miller MR, Hankinson J, Brusasco V, et al. Standardisation of spirometry. Eur Respir J 2005;26:319-38.

13 Enright PL, Studnicka M, Zielinski J. Spirometry to detect and manage chronic obstructive pulmonary disease and asthma in the primary care setting. Eur Respir Mon 2005:31:1-14.

14 Yang G, Fan L, Tan J, et al. Smoking in China: findings of the 1996 National Prevalence Survey. JAMA 1999:282:1247-53.

15 He Y, Jiang B, Li LS, et al. Secondhand smoke exposure predicted COPD and other tobacco-related mortality in a 17-year cohort study in China. Chest 2012;142:909-18.

16 Hazenkamp-von Arx AME, Götschi Fellmann T, Oglesby L, et al. PM2.5 assessment in 21 European study centers of ECRHS II: method and first winter results. J Air Waste Manag Assoc 2003;53:617-28. 
17 Atkinson RW, Kang S, Anderson HR, et al. Epidemiological time series studies of PM2.5 and daily mortality and hospital admissions: a systematic review and meta-analysis. Thorax 2014;69:660-5.

18 Brunekreef B, Forsberg B. Epidemiological evidence of effects of coarse airborne particles on health. Eur Respir J 2005:26:309-18.

19 Tsai SS, Chiu HF, Liou SH, et al. Short-term effects of fine particulate air pollution on hospital admissions for respiratory diseases: a case-crossover study in a tropical city. J Toxicol Environ Health A 2014;77:1091-101.

20 Malig BJ, Green S, Basu R, et al. Coarse particles and respiratory emergency department visits in California. Am J Epidemiol 2013;178:58-69.

21 Kariisa $M$, Foraker $R$, Pennell $M$, et al. Short- and long-term effects of ambient ozone and fine particulate matter on the respiratory health of chronic obstructive pulmonary disease subjects. Arch Environ Occup Health 2015;70:56-62.

22 Kravchenko J, Akushevich I, Abernethy AP, et al. Long-term dynamics of death rates of emphysema, asthma, and pneumonia and improving air quality. Int J Chron Obstruct Pulmon Dis 2014;9:613-27.

23 Pope CA, Ezzati M, Dockery DW. Fine-particulate air pollution and life expectancy in the United States. N Engl J Med 2009;360:376-86.

24 Rabe KF, Hurd S, Anzueto A, et al. Global strategy for the diagnosis, management, and prevention of chronic obstructive pulmonary disease: GOLD executive summary. Am J Respir Crit Care Med 2007;176:532-55.

25 Salvi SS, Barnes PJ. Chronic obstructive pulmonary disease in non-smokers. Lancet 2009;374:733-43.

26 Zhong N, Wang C, Yao W, et al. Prevalence of chronic obstructive pulmonary disease in China: a large, population-based survey. Am J Respir Crit Care Med 2007;176:753-60.
27 Correia M, Magalhães R, Silva MR, et al. Stroke types in rural and urban northern Portugal: incidence and 7-year survival in a community-based study. Cerebrovasc Dis Extra 2013;3:137-49.

28 Schroeder SA. New evidence that cigarette smoking remains the most important health hazard. N Engl J Med 2013;368:389-90.

29 She J, Yang P, Wang Y, et al. Chinese water-pipe smoking and the risk of COPD. Chest 2014;146:924-31.

30 Atkinson RW, Carey IM, Kent AJ, et al. Long-term exposure to outdoor air pollution and the incidence of chronic obstructive pulmonary disease in a national English cohort. Occup Environ Med 2015;72:42-8.

31 Schikowski T, Sugiri D, Ranft U, et al. Long-term air pollution exposure and living close to busy roads are associated with COPD in women. Respir Res 2005;6:152.

32 Rice MB, Rifas-Shiman SM, Litonjua AA, et al. Lifetime exposure to ambient pollution and lung function in children. Am J Respir Crit Care Med 2015;193:881-8.

33 Lepeule J, Bind MA, Baccarelli AA, et al. Epigenetic influences on associations between air pollutants and lung function in elderly men: the normative aging study. Environ Health Perspect 2014;122:566-72.

34 Qun Yu HY. The analysis of the current situation and the variation trend of air quality in Guangzhou. Environ Monit China 2010;26:74-7.

35 Lepeule J, Litonjua AA, Coull B, et al. Long-term effects of traffic particles on lung function decline in the elderly. Am J Respir Crit Care Med 2014;190:542-8.

36 Schikowski T, Adam M, Marcon A, et al. Association of ambient air pollution with the prevalence and incidence of COPD. Eur Respir J 2014;44:614-26.

37 Cao JJ, Shen ZX, Chow JC, et al. Winter and summer PM2.5 chemical compositions in fourteen Chinese cities. J Air Waste Manag Assoc 2012;62:1214-26. 